\title{
USING APPS TO DEVELOP MENTAL CALCULATION IN PRIMARY EDUCATION
}

Samuel Gonçalves, Universidade Aberta, Antonieta Rocha, João Paz, Laboratory of Distance Education \& eLearning (LE@D), Universidade Aberta, Portugal

\section{Abstract}

This research aimed to evaluate the development of mental calculation in Primary Education students promoting the use of the Calculus app in a mobile learning environment. It was observed that children have and use several portable devices with internet connection demonstrating that they are familiarized with technology. Therefore, the immanent pedagogical potential in technology should be used by educational actors towards educational success promoting immersive, contextualized, and centred student learning. Action research was elected as our methodology with planned classroom sessions for the development of mental calculation. It was found that the use of technological resources served educational intentions presenting advantages regarding motivation, feedback, time, concentration, pedagogical differentiation, evaluation, and productivity. This initiative, although not without difficulties, demonstrates that the School must assume its role of mediation of the use of technological resources for the development of school skills.

Keywords: mental calculation, mobile learning, primary education

\section{Introduction}

The development of technology in general and their devices in particular are recognized by all, but not universally embraced by all dependencies and/or instances of society, namely the School.

In a way, the exceptional time arising from the global pandemic caused by Covid-19 made us [re]think the value attributed to the technologies in the education systems. Despite the clear technological gap between school and society, the responsibility to "mediate the process of transformation of information into knowledge" (Tavares \& Barbeiro, 2011; p.7) belongs to the school, since not all citizens exploit this potential. Thus, this role of mediation seems essential in modern times, and like the increasing use of technology in 
other sectors of society such as in the business or sports world, the school environment is the right place to foster the use of technology among students.

In this educational environment, and because we wanted to validate scientifically knowledge that is easily recognized as useful to the teaching practice we carried out an investigation in the field of Mobile Learning to identify eventual potentialities for the development of mental calculation skills in Primary Education. So, the starting research question was:

- May the development of mental calculation in Primary Education be improved using mobile devices?

With greater specificity we outlined the following research objectives:

- Determine whether students' motivation is enhanced by tasks performed on mobile devices.

- Check for increased teacher productivity by improving immediate feedback.

- Understand if the use of mobile devices promotes a good classroom climate.

- Determine whether student performance productivity increases.

- Understand if students have developed their mental calculation.

\section{Context}

The research took place on a class of 13 students of the $3^{\text {rd }}$ grade of Primary Education, aged between 8 and 9 years, in a public school in Azores. Because it is an archipelago of Portugal, cumulatively to the regulating national documents, the educational practice, in this Region, is being guided by the Integrated Plan for the Promotion of Educational Success (ProSucesso - prosucesso.azores.gov.pt) whose action focuses on three axes:

- Axis 1: Focus on the quality of students' learning;

- Axis 2: Promotion of the professional development of teachers;

- Axis 3: Mobilization of the educational community and social partners.

In summary, our investigative intervention focused on the context of mobile learning (m-learning) using the concept of Bring Your Own Device (BYOD) with specific intervention in the curricular area of Mathematics (mental calculation) seeking to assess advantages obtained from the use of mobile devices.

\section{Mobile Learning}

According to Traxler (2015) there has been a growing interest in m-learning observable in the growing number of workshops, conferences and seminars held in several countries: England, Italy, Sweden, Taiwan, and others. 
What is Mobile Learning? Not pretending to offer here an exhaustive treatment of the subject we advance that several authors (Certal \& Carvalho, 2011; Laouris \& Eteokleous, 2005; Sharples et al., 2005; Traxler, 2015) have presented several definitions about the concept of m-learning depending on the variable they emphasize most. In order to systematize the multiple definitions Certal and Carvalho (2011) expose the following perspectives on mlearning: (a) from the technological perspective, m-learning is characterized by being a learning supported by mobile devices; (b) from another perspective, it is regarded as an extension of eLearning via mobile devices; (c) in formal education, m-learning is compared to traditional forms of teaching, not limited to the classroom and finally (d) from the perspective of the student and mobility, m-learning happens whenever there is learning by the student who takes advantage of mobile devices independently the space.

In this research we adopted the position of Dias and Victor (2017) on mobile learning considered as all learning carried out through mobile devices at any time and place, being able, therefore, to speak about omnipresent learning in the $21^{\text {st }}$ century.

In fact, we consider that m-learning is especially directed to the current generation of students whose attention, according to Carvalho (2019) is more difficult to maintain in the classroom. This generation dominates apps, games, social networks, among other interfaces, through their mobile devices and it is in this context that mlearning can intervene to foster the "involvement, responsibility and creativity of students" (Carvalho, 2019; p.2) highlighting, right away, the possibility of a more student focused learning.

It is undeniable that m-learning entails a set of advantages that foster on a large scale the learning and involvement of the student in the construction of his knowledge.

\section{Methodology}

Action Research is a research methodology that was born in the first half of the $20^{\text {th }}$ century whose founder was Kurt Lewin. It presupposes a "new way of making" knowledge by the association of theory with practice (Ferreira, 2008). Melo, Filho, and Chaves (2016) assume that Lewin proposed Action Research as a methodology not only for an on-site study, but for participating in the problem.

Thus, the choice for this methodology means that teachers "study students learning by relating them to their own teaching and, in this sense, it is a process that allows them to learn about their practices in order to improve students learning” (Santos, 2017; p.132). 
It should be noted that the choice for this research methodology was the subject of deep reflection and originated in 3 fundamental premises:

- Problem: Gaps were identified in the school path of the students obtained from the results of the Measurement Tests of the previous school year;

- Researcher: One of the researchers is a teacher of the class chosen as a target audience;

- Pragmatic character: A pragmatic nature of intervention in teaching practice was postulated in order to improve it.

In order to maintain the anonymity of the target audience or the confidentiality of the information provided in the context of this investigation, we chose to proceed with the codification (Table 1). We adopted a simple coding based on the initials of the participants to transcribe some of the observations, speeches and records of the results themselves throughout the analysis of the results. The cardinals from 1 to 13 were added to facilitate understanding for readers.

Table1: $\quad$ Stakeholder Coding

\begin{tabular}{llll}
\hline Typology & Encoding & Date investigation & Applied instruments \\
\hline Students & S & October 2019 & Observation Logbook \\
\hline
\end{tabular}

\section{Results}

The first classroom session was developed using calculus game and followed a very basic configuration involving three distinct moments (groups, pairs and individual); three operations (addition, subtraction and multiplication) and numbers up to 10. In this format, the game applies a limit time of 1 minute, so in general, these moments were short-lived. At the end of each moment, the number of correct answers reached by the students was recorded (Figure 1).

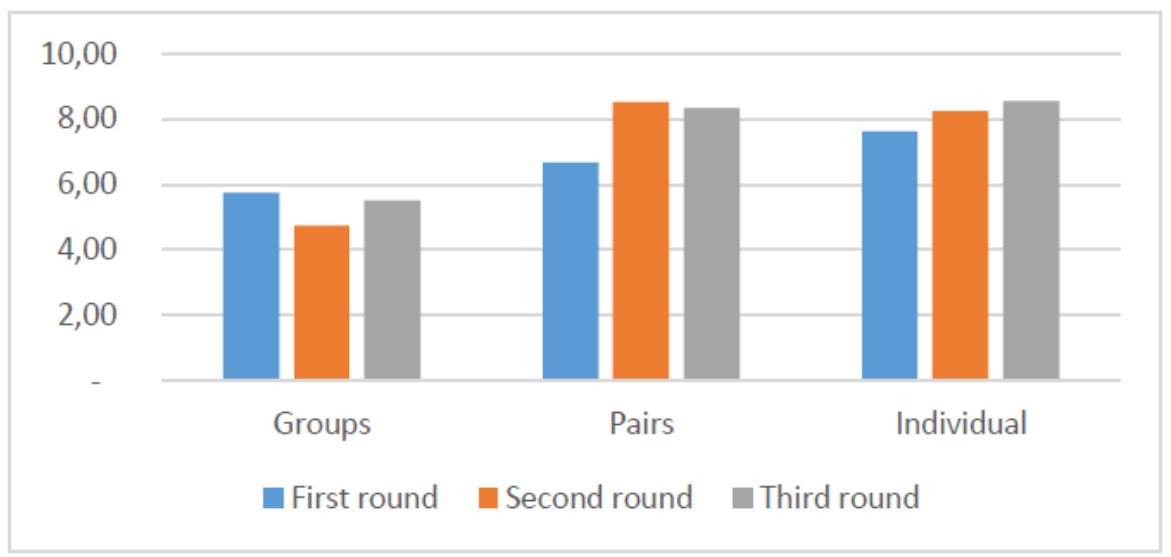

Figure 1. Average number of correct answers in calculus game

Regarding the number of correct answers, it is verified that the phase involving the groups (3 to 4 children) received fewer responses. We deciphered this indicator as part of the 
familiarization with the environment necessary for the Calculus game that was unknown by the students, the multiplicity of the operations involved, the time limit imposed by the game, the dexterity necessary for mental calculation and the various meanings involved in the operations. In this matter, it is important to note that Calculus focuses on several operations in its various senses (Figure2).

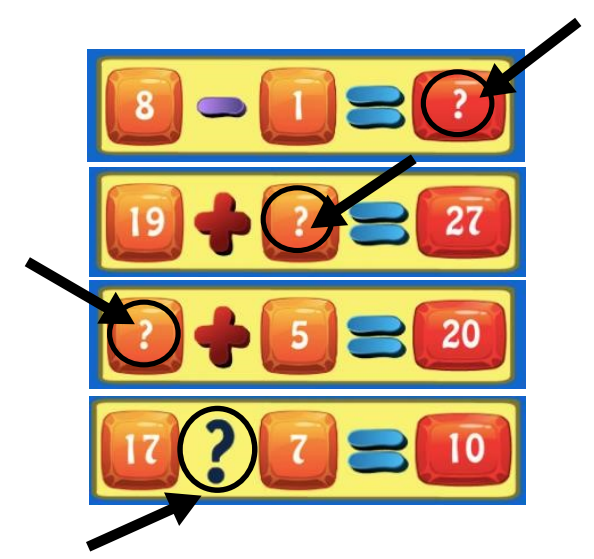

Figure 2. Calculus: multiple senses of operations

The moments in pairs and individual stand out for the positive compared to the group reaching greater record of correct answers and it is still to be noted that the data collected are very similar to each other.

After this session, we have seen some advantages resulting from the use of mobile devices in mathematics:

- Motivation - the use of mobile devices by students, in the context of the classroom, alone, proved to be a motivating element for the tasks to be performed.

- Feedback - students received instant feedback to the answers given which promoted learning and consolidation of the learned contents and competences. It also added encouraging messages such as: "you are on the right track"; "it goes on like this"; "very well"; "splendid"; "show"... which enhanced motivation.

- Time - the number of questions answered in the game is higher than those answered in traditional supports, as they do not involve the transcription of exercises for the notebook, nor moments of waiting for correction.

- Concentration - students were focused on the questions trying to give the right answers to receive higher scores.

- Scoring system - the rankings fostered competition among students. This situation led to a faster response, which in turn is essential in mental calculation.

- Pedagogical differentiation - Pedagogical differentiation is also at a distance click because the choice of the degree of difficulty as well as which operations to select are mirrored in the initial menu of the application. 
- Evaluation - from the observation of the results after each series of questions, the teacher retains a record of the student's level and the progression that is being made.

At the end of this initially planned session and not fully satisfied with the results obtained, we chose to develop two extra sessions. This time, the conditions of the proposed task required configuring the game to include additions and subtractions and numbers up to 20. Under these conditions, the game itself adjusted the time to 2 minutes. Since the students participated in 15 rounds, this comes that for 30 minutes they were focused on practicing exercises that are promoters of mental calculation.

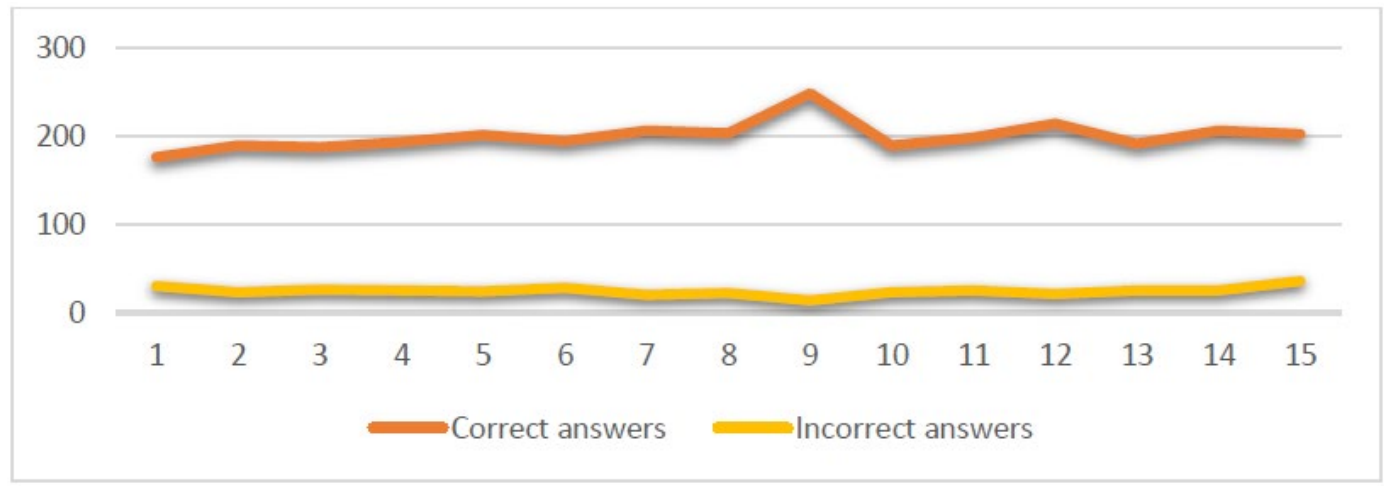

Figure 3. Variation of responses

Regarding the concentration in the activity, it is verified that the amplitude between the correct and incorrect answers is high, which indicates that the students remained focused during the activity (Figure 3).

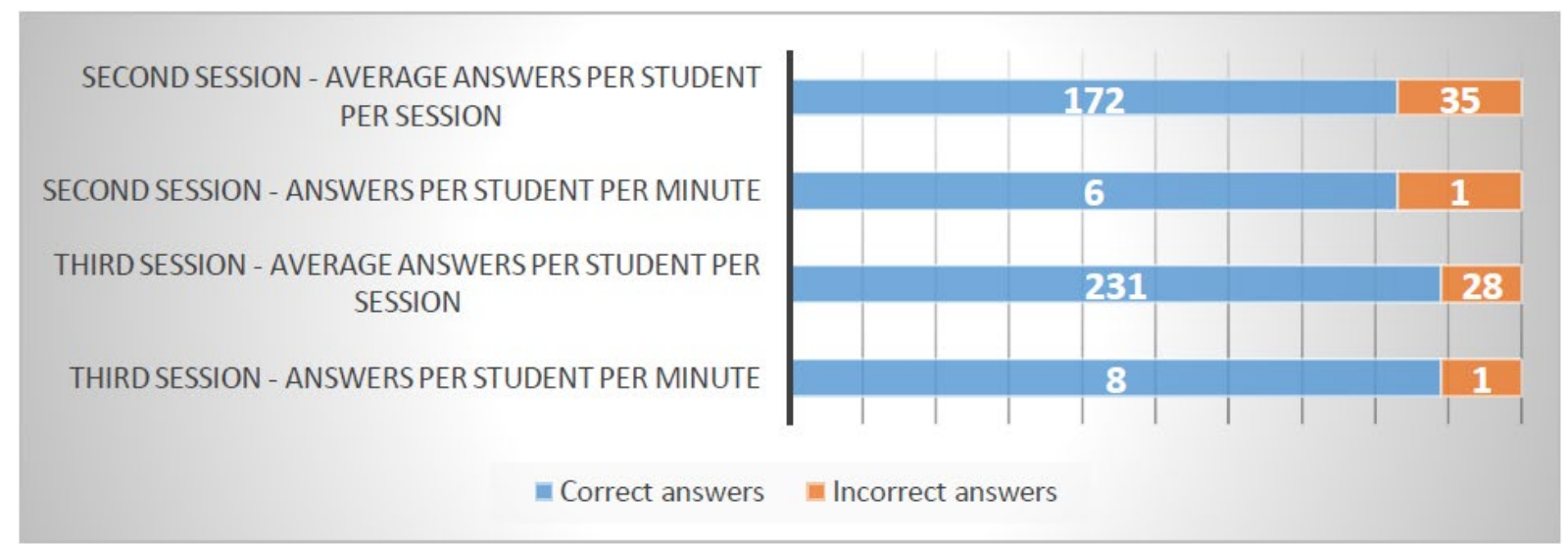

Figure 4. Comparison of correct answers per session and per minute

From the number of answers, we were left with excellent indicators of the work volume produced by the students and of the degree of satisfaction of their own in these about 30 minutes. Based on the comparison of the number of answers as a function of time (Figure 4), we also noticed that from the second to the third session there was an increase of about $34 \%$ in the number of correct answers either per session or per minute and a reduction of incorrect answers in the order of $19 \%$. This data can still be confirmed in the 
relationship between correct and incorrect answers per minute in which there is an improvement in the ratio of 6 to 1 of the second session, to the ratio of 8 to 1 of the third session.

Also during these specific sessions and by observing the activity in the classroom, it was found that the mobile device used by the student conditioned the number of responses, because the devices with touch screen did not lack the handling of the mouse as in the laptops, which, in turn, conditioned the time available for the answers due to the delay in their handling. For this reason, it was suggested to two students, one who used a smartphone and the other who used a laptop, to change devices and to recomplete the task (Figure 5).

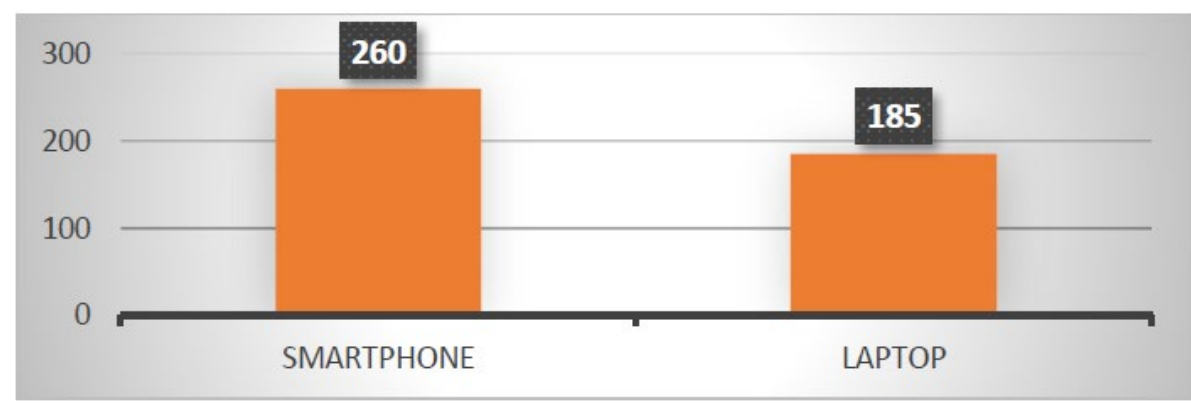

Figure 5. Average responses given in 2 minutes

Regarding the type of mobile device, it can be verified that the answers given on the phone are higher by about $30 \%$ compared to those of the laptop, which validates the observations made in the classroom. It should also be noted that this situation does not interfere with the correction of the answers given, maintaining the same pattern of correction.

Thus, it can be concluded that in the case of the Calculus, which implies the variable time, mobile devices with touch screen are more advantageous in the volume of tasks performed without this implying differences in the correction of them.

These results show the direct influence of the use of mobile devices with applications appropriate to the skills that are sought to develop and, in this case, the Calculus app that promotes the development of mental calculation.

Thus, we consider that the use of mobile devices in properly planned classroom sessions enhances the development of specific competencies in the field of mathematics, promoting increased productivity and motivation; facilitating feedback; and fostering concentration, number of tasks, pedagogical differentiation and evaluation of students. 


\section{Conclusions}

Recalling the starting question, "May the development of mental calculation in Primary Education be improved using mobile devices?", our answer is a categorical "Yes". However, it is not enough to ask students to use mobile devices or just distribute them without any criteria and expect beneficial results $\mathrm{f}$. It is necessary to properly plan the activities involving mobile devices with well-designed objectives for the skills to be developed.

We initially proposed a set of objectives for this research that we now evaluate:

- Determine whether students' motivation is enhanced by tasks performed on mobile devices.

- This goal was easily attainable. We would even say that it is enough to present the task to be performed using mobile devices, that motivation arises instantly. The motivation index was measurable, throughout the investigation, by the verbalizations of the students requesting the use of mobile devices.

- Check for increased teacher productivity by improving immediate feedback.

- We consider that there was an increase in teacher productivity by punctual feedback and final balance provided by the app.

- Understand if the use of mobile devices promotes a good classroom climate.

- After the initial period of setting the mobile devices, we found that the tasks fostered a greater concentration of students, thus contributing to a good classroom climate.

- Determine whether student performance productivity increases.

- This was one of the variables that was most noticed by performing mental calculation tasks on mobile devices.

- Understand if students have developed their mental calculation.

- The ratios obtained in the sessions show that the mental calculation of the students was developed.

\section{References}

Carvalho, A. A. (2019). Apps e Jogos Digitais em Contexto Educativo para Promover Envolvimento, Responsabilidade e Criatividade nos Estudantes. In C. G. Marques, I. Pereira, \& D. Pérez (Eds.), Proceedings of the $21^{\text {st }}$ International Symposium on Computers in Education (SIIE 2019) (pp. 1-6). Instituto Politécnico de Tomar. 
Certal, F. M., \& Carvalho, A. A. A. (2011). Estudo Sobre Receptividade ao M-Learning no Ensino Básico. Paper presented at the VII Conferência Internacional de TIC Na Educação. http://hdl.handle.net/1822/15940

Dias, L., \& Victor, A. (2017). Teaching and Learning with Mobile Devices in the 21st Century Digital World: Benefits and Challenges. European Journal of Multidisciplinary Studies, 2(5), 7.

Ferreira, P. (2008). A Utilização da Metodologia de Investigação-Acção na Intervenção Social: uma reflexão teórica. Revista Intervenção Social, 32(32), 215-236. Retrieved from http://revistas.lis.ulusiada.pt/index.php/is/article/view/1451/1567

Laouris, Y., \& Eteokleous, N. (2005). We need an educationally relevant definition of mobile learning. Cyprus Neuroscience \& Technology Institute. Retrieve from http://citeseerx.ist.psu.edu/viewdoc/download?doi=10.1.1.106.9650\&rep=rep1\&type $=\mathrm{pdf}$

Melo, A. S. E. de, Filho, O. N. M., \& Chaves, H. V. (2016). Lewin e a pesquisa-ação: gênese, aplicação e finalidade. Fractal: Revista de Psicologia, 28(1), 153-159. https://doi.org/10.1590/1984-0292/1162

Santos, J. R. (2017). A investigação-ação e o desenvolvimento de práticas educativas e de liderança educacional conducentes à eficácia nas escolas. Universidade Aberta de Portugal. Retrieved from http://hdl.handle.net/10400.2/8713

Sharples, M., Taylor, J., \& Vavoula, G. (2005). Towards a Mobile Learning Pedagogy. Retrieved from https://www.researchgate.net/publication/228346088_Towards_a_theory_of_mobile_ learning

Tavares, C. F., \& Barbeiro, L. F. (2011). As Implicações das TIC no Ensino da Língua (1 ${ }^{\text {st }}$ ed.). Ministério da Educaçãa - Direção Geral de Inovação e Desenvolvimento Curricular.

Traxler, J. (2015). Defining Mobile Learning. Proceedings of the IADIS International Conference Mobile Learning, 261-266. Retrieved from https://www.researchgate.net/publication/228637407 